\title{
The linear Programming Model of Vegetables Transport Scheme Design
}

\author{
Tian'e Wang, Baocheng Wan*, Cong Xiao and Yicheng Feng \\ Information Technology College \\ Jilin Agricultural University \\ Changchun, 130118, China \\ ${ }^{*}$ Corresponding author
}

\begin{abstract}
Due to many factors, vegetable transportation scheme decision is more complicated, thus we put forward a reasonable and practical meaningful vegetables transport model that has considerable practical significance. Based on the rationality and feasibility of transportation scheme, and the limitation of vegetables supply and demand, we establish the linear programming model, and do AMPL procedure of the model. We calculate the data of vegetables transportation about the city of planting base as an example, the solving speed and the results show the rationality of the model.
\end{abstract}

Keywords- linear programming; dijkstra algorithm; vegetables transport

\section{INTRODUCTION}

To alleviate the contradiction of China's food supply tight, the ministry of agriculture proposed a "vegetable basket project" in 1988, vegetables as the main product, it has been paid much attention by all levels of government. So in order to improve the quality of the products and increase farmers' income, we study a reasonable vegetables transport scheme that has its necessity and urgency. Qian Songdi and other people used the idea of operational research, the required factor is seen as constraints, they built a mathematic model of the vegetable transport, and find out the optimal transport scheme. Xiao Manhong and other people used the transportation problem research of linear programming model, they solved the problem of the delivery of the vegetables. These algorithms are used to solve the problem of ideally transport vegetables. In the presence of certain factors at present are not yet related research.

In this paper, based on the rationality and enthusiasm of vegetable delivery, we do assignment for each supply level corresponding to the distance and need of the sales point, and establish linear programming model about the fees paid. We adopt reasonable constraint optimization, and finally use AMPL to solve the programming. We analyze the results. So we get reasonable shipping vegetables.

\section{PROBLEM DESCRIPTION}

In some small and medium-sized cities, in order to promote the enthusiasm of farmers about growing vegetables and keep the supply of vegetables, to guarantee the supply of vegetables city we often use in combination with the government subsidies. Each vegetables outlets are regularly distributed to every point of sales, and we know the corresponding to the distance between them, compensation expenses, and the number of information

Arrange transport vegetables put vegetable base provide the number of vegetables sales require quantity, and the government's spending, point-of-sale relationship as the goal. We consider the distance between the local supplier to various vegetables demands, capacity constraints, in order to achieve optimal freight. Namely to consider to meet residents' demand for vegetable species, the government spend in vegetables transport freight subsidies minimum, so that residents can get good quality low price of fresh vegetables, farmers are interested to plant vegetables. All in all, vegetables' delivery problems are as far as possible and reasonable.

\section{MODEL}

In this paper, considering the objective factors such as weather that affects vegetable transport does not affect transport cost problem, we assume that demand for point of sales within a short period of time is changeless, and the quality of vegetables in the process of transportation will not change.

This article subsidy costs can be divided into two aspects to consider, namely the vegetables in the process of transportation have to pay shipping costs as well as the compensate shortage fee about the source of supply to the point of sale vegetables. First the government to pay the shipping cost is related to the distance of the corresponding point of sales and vegetables transport units, price and demands. This article uses the dynamic programming in the Dijkstra algorithm to find the shortest path of each supplier to the point of sales, it has given the freight subsidies standards and traffic volume. We can deal with the freight subsidies of the government. Next to cope with the shortage of government subsidies, we consider the relationship of supply and demand of vegetables, and combined with the standards of shortage of subsidies. We get the corresponding shortage of vegetables compensation fees.

Below model used the related symbols, m said the number of vegetable supplier, $\mathbf{n}$ said the number of outlets, $f$ said the freight unit price, $a_{i j}$ said the supply of the land, $b_{i j}$ said demand for point of sales, $c_{i j}$ said the shortage compensation standard, $d_{i j}$ said the distance from planting base to the point of sales, $e_{i j}$ said vegetables traffic mounts, $q_{i j}$ said vegetables 
shortage of sales, $p_{i}$ said vegetables demand increase, $z$ said the government spending, $x$ said the percentage of the requirements of vegetables point-of-sale of the demands for vegetables.

This paper uses the Dijkstra algorithm to find the distance from the point of sales to point-of-sale demands. Combined with the freight unit price, we know the demands of sales and get the corresponding freight subsidies. We suppose the quality vegetables that are sent is changed. We should not consider the weather and other objective factors. Finally given the supply of vegetables outlets and freight unit price in the process of transporting, subsidies standards of shortage vegetables. Considering various factors, we add to the two kinds of cost, making them to ask the sum of the optimal conditions. So the objective function can be represented as:

$$
\min z=\sum_{i=1}^{m} \sum_{j=1}^{n} f \cdot d_{i j}=e_{i j}+\sum_{i=1}^{m} \sum_{j=1}^{n}\left(b_{i j}-a_{i j}\right) \cdot c_{i j}
$$

Need to satisfy the constraint conditions:

1) according to the actual situation, the supply, demand and traffic of vegetables must exist, namely

$$
a_{i j} \geq 0, b_{i j} \geq 0, c_{i j} \geq 0
$$

2) to keep the vegetables fresh and decrease the shortage of vegetables, as far as possible to reduce the shortage cost, we need to meet each point of sales volume that is equal to the supply, namely

$$
e_{i j}=b_{i j}
$$

3) consider farmers about the enthusiasm of vegetables, the demand is greater than or equal to supply, namely

$$
b_{i j} \geq a_{i j}
$$

4) consider the demand for vegetables point-of-sale sometimes has certain limitations, namely

$$
a_{i j} \geq b_{i j} x
$$

According to the (2) to (5) about the objective function and reasonable planning of constraint conditions, we can obtain the optimal vegetables transportation arrangement plan.

To sum up, in this paper, we consider the reasonable factors of the overall planning and establish optimization model as follows:

$$
\begin{gathered}
\min z=\sum_{i=1}^{m} \sum_{i=1}^{n} f \cdot a_{i j} \cdot e_{i j}+\sum_{i=1}^{m} \sum_{j=1}^{n}\left(b_{i j}-a_{i j}\right) \cdot c_{i j} \\
\text { s.t. }\left\{\begin{array}{c}
e_{i j}=b_{i j} \\
b_{i j}>a_{i j} \\
e_{i j}, b_{i j}, a_{i j} \geq 0
\end{array}\right.
\end{gathered}
$$

\section{EXAMPLE}

\section{A. Random Data to Solve}

Based on the data analysis and modeling, we need to use specific data to verify the efficiency and rationality. In order to verify the universality and comprehensiveness of model, we need to use a large number of different size of random data. We use programming language to implement the data from vegetable gardens to the sales, the concrete implementation process is shown as follows:

Because in the process of the vegetable transport, vegetables transport quantity, vegetable gardens to the distance of the sales, the demand in sales for vegetable is different, but there are certain restrictions. In a certain period of time, for example, the number of trucks carrying vegetables is certain. Therefore, within the prescribed time, randomly it generates a set of vegetable demand and production information between vegetable gardens and sales.

Finally, with the generated random data of different size, we solve into the model. According to the rationality of the analysis of model improvement and the solving time, we improve it.

\section{B. Instance to Solve}

Using $2015 \mathrm{Ji}$ Lin province E problem of mathematical contest in modeling data, the optimization model is built to find the solution to this instance. Combining with AMPL software coding, we get a reasonable transportation arrangement of vegetables. The instance has eight vegetables planting bases and 35 outlets, using AMPL program for each vegetable gardens to the sale, the optimal transportation plan as follows, $(i, j, v)$ said vegetable base $i$ supply outlets $j$ vegetables of $v$ tons:

$(1,4,14.3),(1,5,13),(1,12,0.69),(1,14,12),(2,12,6.31)$,

$(2,13,8.5),(2,15,11.6),(2,16,12.5),(2,17,13.5),(2,18$, $0.04),(2,23,6.7),(2,25,0.24),(2,26,15),(3,24,4.53),(3,25$, 9.36), (3, 27, 7.2), (3, 28, 8.9), (4, 24, 7.98), (4, 29, 10.3), (4, 30, 9),

$(4,31,0.01),(4,35,10.7),(5,31,7.69),(5,32,8),(5,33,11.4)$, $(5,34,12.1),(6,7,5.71),(6,8,9.5),(6,9,10),(6,10,8.4)$,

$(6,11,5.51),(6,18,8.96),(6,19,7.3),(6,20,10),(6,21,12.7)$, $(6,22,7.4),(7,1,6.5),(7,2,10.2),(7,7,8.29),(8,3,12)$,

$$
(8,6,11),(8,11,4.99) \text {. }
$$

Based on the complexity on the allocation of the vegetable transportation scheme, considering the limitation on the 
demand and cost in the process of transportation, we establish the linear programming model, and then with the example of real data to applicate. It verify the feasibility and rationality of vegetables distribution, it has a certain value to improve the efficiency of vegetable distribution. And the allocation for the scheme of fundamental equilibrium of 35 local vegetable distribution is reasonable. But because of the current vegetable gardens in the sales, the distribution of the vegetables is also different, and the data aspect also has certain limitation, as a result, the model in practice remains to be further improved in the future.

\section{CONCLUSION}

According to the date of city vegetable base and point-ofsale, we use the established optimization model, simulate vegetables transport process. We process the data and applicate reasonable, using AMPL software powerful solution, it obtains satisfactory results. In addition, this model can be applied to transport scheme decision of the vegetables in each region. To improve the efficiency of vegetable transport, reduce the costs of vegetables transport, it has a certain practical significance.

\section{REFERENCES}

[1] Qian Songdi, 《operations research》, Beijing: Qing Hua university press, 2005.

[2] Jiang Qiyuan, 《mathematical model》, Beijing: higher education press, 2011.

[3] Huang Ping, 《the optimization theory and method》, Beijing: Qing Hua university press, 2009.

[4] Xiao Manhong, 《 based on the linear programming model of transportation problem research $\rangle$, tianjin: Tian Jin vocational college journal of joint, 2012.7

[5] Robert Fourer, David M. Gay, Brian w. Kernighan. AMPL: A Modeling Language for Mathematical Programming (Second Edition). Boston: Cengage Learning, 2002. 